\title{
Umbilical Vein Oxytocin Injection versus Umbilical Cord Drainage in Management of Third Stage of Normal Vaginal Delivery: A Randomized Controlled Trial
}

\author{
Mohamed El-Bakry Lashin \\ Department of Obstetrics and Gynecology, Faculty of Medicine, Zagazig University, Zagazig, Egypt \\ Email: elbakrylashin@yahoo.com
}

How to cite this paper: El-Bakry Lashin, M. (2020) Umbilical Vein Oxytocin Injection versus Umbilical Cord Drainage in Management of Third Stage of Normal Vaginal Delivery: A Randomized Controlled Trial. Open Journal of Obstetrics and Gynecology, 10, 634-643.

https://doi.org/10.4236/ojog.2020.1050057

Received: April 16, 2020

Accepted: May 4, 2020

Published: May 7, 2020

Copyright $\odot 2020$ by author(s) and Scientific Research Publishing Inc. This work is licensed under the Creative Commons Attribution International License (CC BY 4.0).

http://creativecommons.org/licenses/by/4.0/

\begin{abstract}
Objectives: Postpartum hemorrhage is an important cause of maternal morbidity and mortality worldwide. Different preventive strategies were tried to determine the best approach for the management of the 3rd stage of labour. We aim to determine the effect of umbilical vein oxytocin injection and umbilical cord drainage in the management of third stage of labour in normal vaginal delivery. Patients and Methods: One hundred twenty three (123) females were enrolled into this randomized controlled trial. They were aligned into three groups: 1st group (I) (cord drainage group), 2nd group (II) (oxytocin group) and 3rd group (III) (control cord traction group). The primary outcomes were duration of 3rd stage and blood loss. Results: Both group I and II had statistically significant shorter third stage duration than patients of group III $(\mathrm{p}<0.001)$. Mean \pm SD $(7.3 \pm 3.45,4.6 \pm 1.74,9.4 \pm 3.67)$ respectively for groups I, II, III. Also, both group I and II had statistically significant less blood loss than patients of group III $(\mathrm{p}<0.001)$. Conclusion: The current study demonstrated that umbilical vein oxytocin injection and umbilical cord drainage significantly reduce the duration and amount of blood loss in the 3 rd stage of labour, thus, reducing the risk of post partum hemorrhage.
\end{abstract}

\section{Keywords}

Umbilical Cord Drainage, Umbilical Vein, Oxytocin Injection, Third Stage of Labour

\section{Introduction}

Postpartum hemorrhage is a significant cause of both maternal morbidity and 
mortality. Considerable divergence of opinion exist as regarding the best approach for the management of the 3rd stage of labour, this varies between countries and units [1].

The third stage of labour is considered to start when delivery of the fetus is completed and ended when placenta and membranes have been expelled, this normally takes between 5 - $10 \mathrm{~min}$, if longer than $30 \mathrm{~min}$, it should be regarded as prolonged [2].

Complications may occur unexpectedly at this stage \& unless prompt action is taken to control the situation, serious maternal morbidity \& sometimes mortality may occur. Post partum hemorrhage and retained placentas are the commonest complications that may occur in this period [3]. Umbilical vein oxytocin injection is the delivery of oxytocin directly into retro placental myometrium by injecting the substance into the placental bed through the umbilical vein [4].

Umbilical cord drainage includes clamping then cutting of the umbilical cord following baby delivery and after that unclamping, immediately the maternal side of the cord; allowing the blood to drain freely from the placenta. It has been suggested that draining blood from the placental cord reduces its bulkiness, allowing the uterus to contract and retract, thus facilitating placental delivery [5].

\section{Aim of the Work}

The aim of the study is to determine the effect of umbilical vein oxytocin injection and umbilical cord drainage in the management of third stage of labour in normal vaginal delivery.

\section{Patients and Methods}

This study is a randomized controlled trial that was carried out in Department of Obstetrics \& Gynecology at Zagazig University Hospitals, Sharkia, Egypt and in some private centers during the period from September 2019 to March 2020.

The patients were aligned into three groups: 1st group (I) (cord drainage group), 2nd group (II) (oxytocin group) and 3rd group (III) (control cord traction group).

The patients were randomized using computerized random tables as we assigned the even number to the control group (group III) while the odds numbers divided in between the two other interference groups as the first case assigned to group I and next to group II.

The sample size was calculated using open.Epi-7, assuming that the third stage duration among group used intra-umbilical oxytocin was $3.51 \pm 2.97$ min versus $2.3 \pm 1.91$ min among group with umbilical drainage, power of study $80 \% \& \mathrm{CI}$ $95 \%$. So, the sample size found to be 123,41 cases in each group.

Prior to conducting the study, ethical approval was obtained from Zagazig faculty of Medicine Research and Ethics Committee.

\subsection{Inclusion Criteria}

The study included (123) pregnant women with the following criteria: 
- Gestational age between (36 - 40) completed weeks as determined by last menstrual period and/or early ultrasound scan.

- Mode of delivery: Normal vaginal delivery.

- Single fetus.

- Vertex presentation.

- Viable fetus.

- Vitally stable.

\subsection{Exclusion Criteria}

- Multiple pregnancy.

- Any other presentation than vertex.

- Previous uterine scar.

- Patient with current medical disorders.

- Patient with bad obstetrical history.

- Presence of chorioamnionitis.

- History of ante partum hemorrhage in present pregnancy.

- Patient with polyhydramnios.

All cases who met inclusion criteria were subjected to the following:

The patients were admitted where detailed history, full medical and obstetric examination was carried out. Before introducing in this study a written consent was obtained from all patients.

During labour, all patients were followed every $2 \mathrm{hrs}$ for pulse rate, blood pressure and temperature.

The females in the first group underwent placental drainage immediately following delivery. This included, placental cord clamping then cutting after the baby has been delivered followed by unclamping of the maternal side.

For second group, a sterile $20 \mathrm{ml}$ syringe already prepared containing $20 \mathrm{IU}$ of oxytocin diluted in $20 \mathrm{ml}$ normal saline $(0.9 \% \mathrm{NaCl})$ was injected directly into umbilical vein after delivery of the fetus and clamping of umbilical cord under aseptic technique.

Umbilical vein was chosen rather than umbilical artery because umbilical vein is single and wider, also injection into the artery cause vascular constriction that does not occur in the vein.

After injection, milking of the cord was done in an upward direction to push the solution up into the placenta, then waiting for signs of placental delivery.

No intervention was carried out to the women in third group (control group). The placenta was delivered by controlled cord traction after the appearance of clinical signs of placental separation.

After placental delivery, it was examined to see if there is no missing cotyledon.

The duration of the 3rd stage was calculated from complete fetal delivery till placental delivery.

The amount of blood lost was calculated from the blood collected into a plastic bag, situated under the woman's buttocks immediately after delivery and 
drained into a stainless-steel recipient till placental delivery.

Patients was observed for the $\mathbf{1 2}$ hours post partum for vital signs, presence of post partum complications, systemic signs, bleeding or passage of placental tissue from vagina.

Before discharge each patient was counseled to notice any bleeding, abdominal pain or discomfort, fever, vaginal discharge, and passage of any tissue through the vagina, if any occurred, they were asked to return to hospital immediately.

\subsection{Statistical Analysis}

Data were analyzed using IBM SPSS 23.0 for windows (SPSS Inc., Chicago, IL, USA) and NCSS 11 for windows (NCSS LCC., Kaysville, UT, USA). Quantitative data were expressed as mean \pm standard deviation (SD). Qualitative data were expressed as frequency and percentage.

The following tests were done:

- ANOVA analysis of variance (F test) of significance was used when comparing between more two means.

- Krusskal-Wallis test used when comparing more than two means of not normally distributed data.

- Mann-Whitny test was used when comparing two means of not normally distributed data.

- Fisher Exact test is a test of significance that is used in the place of chi square test in 2 by 2 tables, especially in cases of small samples.

- Probability (p-value): p-value $<0.05$ was considered significant, p-value $<$ 0.001 was considered as highly significant and $p$-value $>0.05$ was considered insignificant.

\section{Results}

During the period of the study, 123 cases were enrolled; their basic characteristics are presented in Table 1 . There was no statistical significant difference among three studied groups as regarding age of mothers, parity, gestational age and birth weight of babies.

Both group I and II had statistically significant shorter third stage duration than patients of group III $(\mathrm{p}<0.001)$. Mean \pm SD $(7.3 \pm 3.45,4.6 \pm 1.74,9.4 \pm$ 3.67) respectively for groups I, II, III.

Also, both group I and II had statistically significant less blood loss than patients of group III $(\mathrm{p}<0.001)$ (Table 2, Figure 1, Figure 2).

There was a statistical significant difference in between three studied groups as regard third stage duration and amount of blood loss $(\mathrm{p}<0.001)$ (Table 3 ).

Only one case from group I and 2 cases from group III needed blood transfusion with no statistically significant difference between groups $(p=0.36)$.

Three cases from group I, One case from group II and 2 cases from group III needed oxytocin with no statistically significant difference between groups $(\mathrm{p}=$ 0.59) (Table 4). 
Table 1. Basic characteristics of the studied groups.

\begin{tabular}{cccccc}
\hline Variables & Group I & Group II & Group III & F test & p-value \\
& $\mathrm{N}=41$ & $\mathrm{~N}=41$ & $\mathrm{~N}=41$ & & \\
\hline Age/years & & & & & \\
Mean \pm SD & $27.6 \pm 4.71$ & $26.3 \pm 5.11$ & $25.5 \pm 4.39$ & 1.98 & 0.143 \\
Range & $18-37$ & $18-37$ & $19-34$ & & NS \\
& & & & & \\
Gestational age/weeks & $37.9 \pm 1.53$ & $37.7 \pm 1.37$ & $38.1 \pm 1.54$ & 0.56 & 0.57 \\
Mean \pm SD & $36-40$ & $36-40$ & $36-40$ & & NS \\
Rang & & & & & \\
Parity & $2.5 \pm 1.25$ & $2.3 \pm 1.07$ & $2.4 \pm 1.14$ & 0.46 & 0.63 \\
Mean \pm SD & $2-5$ & $1-5$ & $1-5$ & & NS \\
Range & & & & & \\
Birth weight/gm & $3068.3 \pm 335.6$ & $2946.3 \pm 419.5$ & $2958.5 \pm 418.3$ & \multirow{2}{*}{1.19} & 0.306 \\
Mean \pm SD & $2400-3900$ & $2400-4000$ & $2500-4000$ & & Ns \\
Range & & & & & \\
\hline
\end{tabular}

Table 2. Different clinical outcomes of the studied groups.

\begin{tabular}{ccccc}
\hline Variables & $\begin{array}{c}\text { Group I } \\
\mathrm{N}=41\end{array}$ & $\begin{array}{c}\text { Group II } \\
\mathrm{N}=41\end{array}$ & $\begin{array}{c}\text { Group III } \\
\mathrm{N}=41\end{array}$ & p-value \\
\hline Third stage duration/min. & & & & \\
Mean \pm SD & $7.3 \pm 3.45$ & $4.6 \pm 1.74$ & $9.4 \pm 3.67$ & $<0.001^{*}$ \\
Range & $3-15$ & $2-8$ & $3-20$ & HS \\
Median & 7 & 5 & 9 & $<0.001^{*}$ \\
Blood loss/ml & & & & HS \\
Mean \pm SD & $265.2 \pm 95.3$ & $183.9 \pm 29.3$ & $345.9 \pm 105.2$ & $190-730$ \\
Rang & $150-650$ & $140-270$ & 320 & \\
Median & 280 & 180 & & \\
\hline
\end{tabular}

Table 3. Multiple comparisons in between studied groups.

\begin{tabular}{ccccc}
\hline Variables & $\begin{array}{c}\text { Median difference } \\
\text { Group I With }\end{array}$ & ${ }^{*} \mathrm{MW}$ & $\begin{array}{c}\text { Mean difference } \\
\text { Group II With }\end{array}$ & ${ }^{*} \mathrm{MW}$ \\
\hline Third stage duration/min. & Group II & $<0.001$ & Group III & $<0.001$ \\
& Group III & 0.01 & Group III & $<0.001$ \\
\hline
\end{tabular}

Table 4. Difference in assessment data of the studied groups.

\begin{tabular}{ccccc}
\hline Variables & $\begin{array}{c}\text { Group I } \\
\mathrm{N}=41\end{array}$ & $\begin{array}{c}\text { Group II } \\
\mathrm{N}=41\end{array}$ & $\begin{array}{c}\text { Group III } \\
\mathrm{N}=41\end{array}$ & p-value \\
\hline $\begin{array}{c}\text { Need for blood transfusion } \\
\text { N (\%) }\end{array}$ & $1(2.4 \%)$ & $0(0.0 \%)$ & $2(4.9 \%)$ & $\begin{array}{c}0.36^{*} \\
\mathrm{NS}\end{array}$ \\
$\begin{array}{c}\text { Need for oxytocin } \\
\text { N (\%) }\end{array}$ & $3(7.3 \%)$ & $1(2.4 \%)$ & $2(4.9 \%)$ & $\begin{array}{c}0.59^{*} \\
\mathrm{NS}\end{array}$ \\
\hline
\end{tabular}

${ }^{*}$ Fisher exact test of significance. NS: p-value $>0.05$ is not significant. 


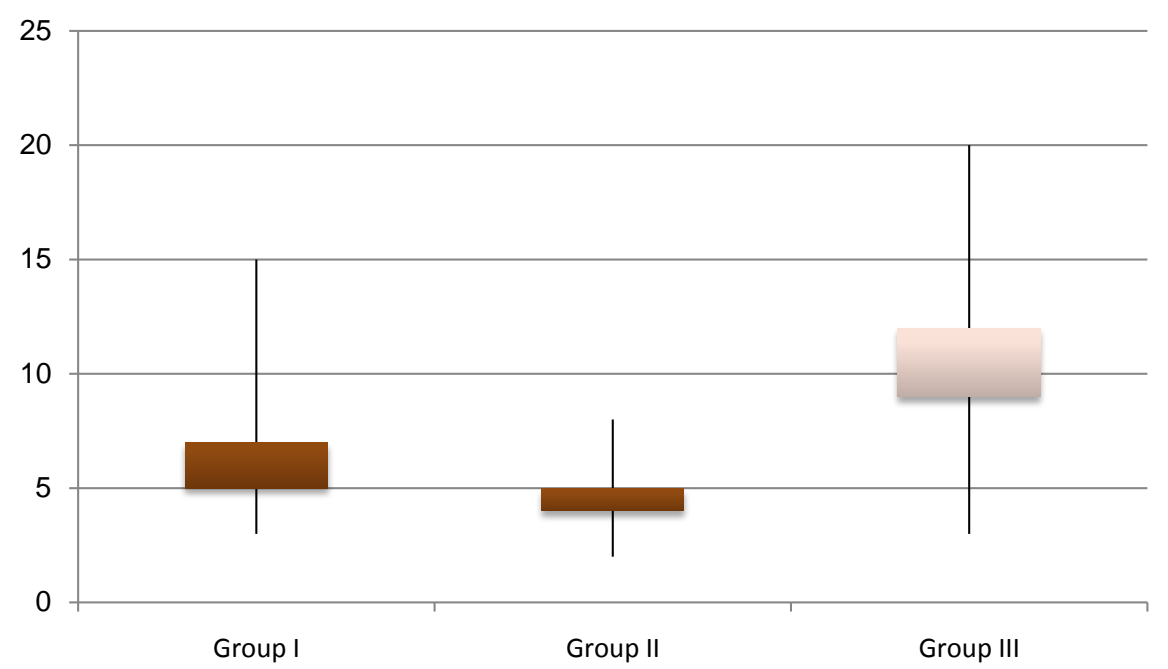

Figure 1. Box plot analysis of third stage duration among studied groups $(p<0.001)$. ${ }^{\star}$ Krusskal-Wallis test of non-parametric data; HS: $\mathrm{p}$-value $<0.001$ is high significant.

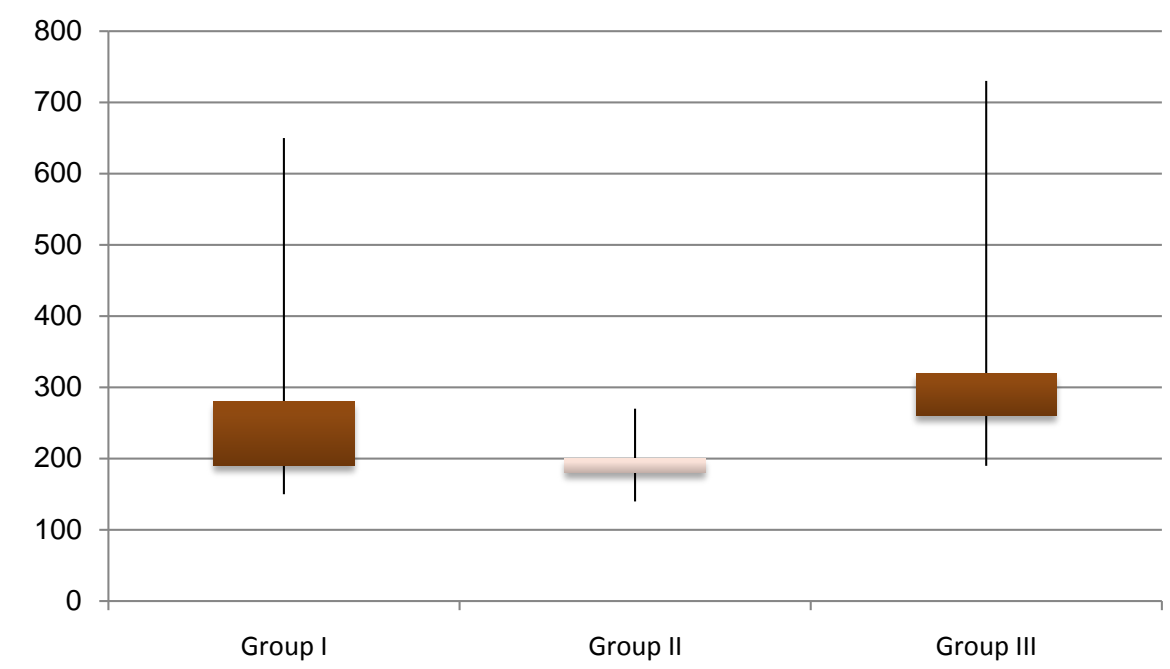

Figure 2. Box plot analysis of blood loss among studied groups $(\mathrm{p}<0.001)$. ${ }^{\star}$ Krusskal-Wallis test of non-parametric data; HS: p-value $<0.001$ is high significant.

\section{Discussion}

Postpartum hemorrhage is the major cause of maternal mortality globally. So, the active management during the third stage of labor is recommended as a preventive measure. Active management includes measures that reduce duration and blood loss which occurs in this stage [1].

Immediate cord clamping and uterotonics are proposed techniques. A different strategy for accelerating uterine emptying is placental cord drainage [5].

Golan et al., 2003 [6] proposed that the intra umbilical vein oxytocin injection makes a high level of oxytocin in the wall of the uterus, so accelerate placental expulsion.

Our study used umbilical cord drainage and intra umbilical vein oxytocin injection in the 3rd stage of labour and compared them with control group. 
We reported that umbilical cord drainage group has a significant shorter duration and less blood loss in 3rd stage compared to control group $(\mathrm{p}<0.001)$.

This was in concordance with previous studies that suggested placental cord drainage reduces the third stage duration and blood loss [5] [7] [8] [9].

Also, Jongkolsiri, P. et al., 2009 [10] performed a randomized clinical trial, that included 49 female in intervention group and 50 females as a control group. They reported a significant shorter duration of third stage after cord drainage (5.1 \pm 2.4 versus $7.0 \pm 6.1$ minutes).

In contrast to our study, a recent randomized clinical trial by Vasconcelos, F.B. et al., 2018 [11] proved that placental cord drainage had no significance in reducing the duration or blood loss in the third stage of labor.

Considering volume of blood loss with placental cord drainage, previous study results vary. One study randomized 200 women to placental drainage compared to maintaining the cord clamped, the blood loss was less in the first group (175 versus $252 \mathrm{ml}$ ) [12].

In another study by Asicioglu, O. et al., 2015 [13] with a large sample size (485 females), the amount of lost blood was one of the primary analyzed outcomes. The study found that blood loss was less in placental cord drainage (207 versus $277 \mathrm{ml}, \mathrm{p}<0.001)$.

The effect of placental cord drainage on the third stage of labor was studied by the Cochrane database of systemic reviews. They have chosen randomized trials that involved placental cord drainage as a variable in the package of intervention for third stage of labor management and found that cord drainage cause significant reduction in the duration of the third stage of labor [14].

Sharma et al., 2005 [15] studied 958 women with vaginal delivery. They were randomized into 2 groups: drainage group ( 478 females) and controlled cord traction group (480 females). The mean duration of third stage of labor was 3.24 minutes and 3.2 minutes in the first group versus $8.57 \mathrm{~min}$ and $6.2 \mathrm{~min}$ in second group for primigravida and multigravida respectively.

A recent meta-analysis that included 9 studies with 2653 patients reported that the 3rd stage duration is shorter (2.28 minutes) but blood loss was the same with the application of umbilical cord drainage [16].

As regarding the group of intra-umbilical oxytocin injection, our study reported statistically significant shorter duration of 3rd stage and less blood loss compared to control group.

Inta-umbilical oxytocin dose can vary from $10 \mathrm{IU}$ to $100 \mathrm{IU}$ [14] with no side effects. We used in our study $20 \mathrm{IU}$ oxytocin in $20 \mathrm{ml}$ of normal saline, given after cord clamping immediately, by direct 21 gauge needle proximal to the clamp. It can be also administered by other method such as feeding tube or intra umbilical catheter via the umbilical vein.

Oxytocin in high concentration stimulates uterine muscle contraction with reduction of the placental implantation site area, resulting in placental cleavage [17]. 
Our results were consistent with Reddy, V.V. and Carey, J.C., 2009 [18] who compared between umbilical vein oxytocin injection (25 patients) with traditional management of the 3rd stage of labour (25 patients). They found cases who received oxytocin via intra-umbilical injection had a significantly shorter duration of 3rd stage of labour, so it is a useful alternative to traditional management and this is in agreement to our study.

Another study by Dahiya, P. et al., 2005 [19] compared intra-umbilical oxytocin injection in 50 patients with traditional management in other 50 patients by the use of $10 \mathrm{IU}$ oxytocin diluted in $20 \mathrm{ml}$ saline. They reported statistically significant shorter third stage of labour and less blood loss in oxytocin group.

We also analyzed other outcomes as need for postpartum oxytocin and blood transfusion with no statistically significant differences was found between the three groups. This was consistent with Vasconcelos, F.B. et al., 2018 [11]. Yet, comparison with the other studies results was impossible because none of them had included these variables.

One of the strong points of the study is the measurement of blood volume loss; so, eliminating observer bias. Another point of strength is that placental cord drainage or intra-umbilical oxytocin injection were the only analyzed techniques, i.e. the only difference in the applied procedures to the groups.

On the other hand, there may be some possible limitations of our study as the limited number of patients. Also, that the females included are at a low risk for the event. So, we recommend a study on large scale with inclusion of high-risk women.

\section{Conclusion}

The current study demonstrated that umbilical vein oxytocin injection and umbilical cord drainage significantly reduce the duration and amount of blood loss in the 3rd stage of labour, thus, reducing the risk of post partum hemorrhage.

\section{Conflicts of Interest}

The authors declare no conflicts of interest regarding the publication of this paper.

\section{References}

[1] Gogarten, W. (2011) [Post partumhemorrhage: An Update]. Anasthesiol Intensivmed Notfallmed Schmerzther, 46, 508-514. https://doi.org/10.1055/s-0031-1284470

[2] Herman, A., Weinraub, Z., Bukovsky, I., et al. (2003) Dynamic Ultrasonographic Imaging of the Third Stage of Labor: New Perspectives into Third Stage Mechanism. American Journal of Obstetrics \& Gynecology, 168, 1496-1499. https://doi.org/10.1016/S0002-9378(11)90788-1

[3] Baker, P.N. (2011) Obstetrics by Ten Teachers, London. 19th Edition, Hodder Arnold a Member of the Hodder Headline Group, 191-192.

[4] Weeks, A.D. (2005) The Retained Placenta. In: Studd, J., Ed., Progress in Obstetric and Gynaecology 16, Elsevier Churchill Livingstone, Edinburgh, 133. 
[5] Soltani, H., Poulose, T.A. and Hutchon, D.R. (2011) Placental Cord Drainage after Vaginal Delivery as Part of the Management of the Third Stage of Labour. Cochrane Database of Systematic Reviews, CD004665. https://doi.org/10.1002/14651858.CD004665.pub3

[6] Golan, A., Lider, A.L., Wexler, S., David, M.P., et al. (2003) A New Method for Management of Retained Placenta. American Journal of Obstetrics \& Gynecology, 146, 708-709. https://doi.org/10.1016/0002-9378(83)91015-3

[7] Giacalone, P.L., Vignal, J., Daures, J.P., Boulot, P., Hedon, B. and Laffargue, F. (2000) A Randomised Evaluation of Two Techniques of Management of the Third Stage of Labour in Women at Low Risk of Postpartum Haemor-Rhage. BJOG: An International Journal of Obstetrics and Gynaecology, 107, 396-400. https://doi.org/10.1111/j.1471-0528.2000.tb13236.x

[8] Begley, C.M., Gyte, G.M., Devane, D., Mc Guire, W. and Weeks, A. (2011) Active versus Expectant Management for Women in the Third Stage of Labour. Cochrane Database of Systematic Reviews, CD007412.

[9] Roy, P., Sujatha, M.S., Bhandiwad, A., Biswas, B. and Chatterjee, A. (2016) Placental Blood Drainage as a Part of Active Management of Third Stage of Labour after Spontaneous Vaginal Delivery. The Journal of Obstetrics and Gynecology of India, 66, 242-245. https://doi.org/10.1007/s13224-016-0857-3

[10] Jongkolsiri, P. and Manotaya, S. (2009) Placental Cord Drainage and the Effect on the Duration of Third Stage Labour, a Randomized Controlled Trial. Journal of the Medical Association of Thailand, 92, 457-460.

[11] Vasconcelos, F.B., Katz, L., Coutinho, I., Lins, V.L. and de Amorim, M.M. (2018) Placental Cord Drainage in the Third Stage of Labor: Randomized Clinical Trial. PLoS ONE, 13, e0195650. https://doi.org/10.1371/journal.pone.0195650

[12] Shravage, J.C. and Silpa, P. (2007) Randomized Controlled Trial of Placental Blood Drainage for the Prevention of Postpartum Hemorrhage. The Journal of Obstetrics and Gynecology of India, 57, 213-215.

[13] Asicioglu, O., Unal, C., Asicioglu, B.B., Temizkan, O., Yildirõm, G., Arici, B. and Gulova, S. (2015) Influence of Placental Cord Drainage in Management of the Third Stage of Labor: A Multicenter Randomized Controlled Study. American Journal of Perinatology, 32, 343-350. https://doi.org/10.1055/s-0034-1384639

[14] Heinonen, P.K. and Pihkala, H. (2005) Pharmacologic Management and Controlled Cord Traction in the Third Stage of Labour. American Journal of Clinical Oncology, 197, 31 .

[15] Sharma, J., Pundir, P., Malhotra, M. and Arora, R. (2005) Evaluation of Placental Drainage as a Method of Placental Delivery in Vaginal Deliveries. Archives of $G y-$ necology and Obstetrics, 271, 343-345. https://doi.org/10.1007/s00404-004-0619-9

[16] Wu, H.L., Chen, X.W., Wang, P. and Wang, Q.M. (2017) Effects of Placental Cord Drainage in the Third Stage of Labour: A Meta-Analysis. Scientific Reports, 7, 7067. https://doi.org/10.1038/s41598-017-07722-7

[17] Gazvani, M.R., Luckas, M.J.M., Darkeley, A.J., et al. (2008) Intraumbilical Oxytocin for Management of Retained Placenta: A Randomized Controlled Trial. Obstetrics \& Gynecology, 41, 3-6.

[18] Reddy, V.V. and Carey, J.C. (2009) Effect of Umbilical Vein Oxytocin on Puerperal Blood Loss and Length of Third Stage of Labour. American Journal of Obstetrics and Gynecology, 161, 206-208. https://doi.org/10.1016/0002-9378(89)90122-1

[19] Dahiya, P., Puri, M., Rathee, S., et al. (2005) Umbilical Vein Oxytocin in 3rd Stage of Labour. Indian Journal f Medical Sciences, 49, 23. 


\section{Appendix}

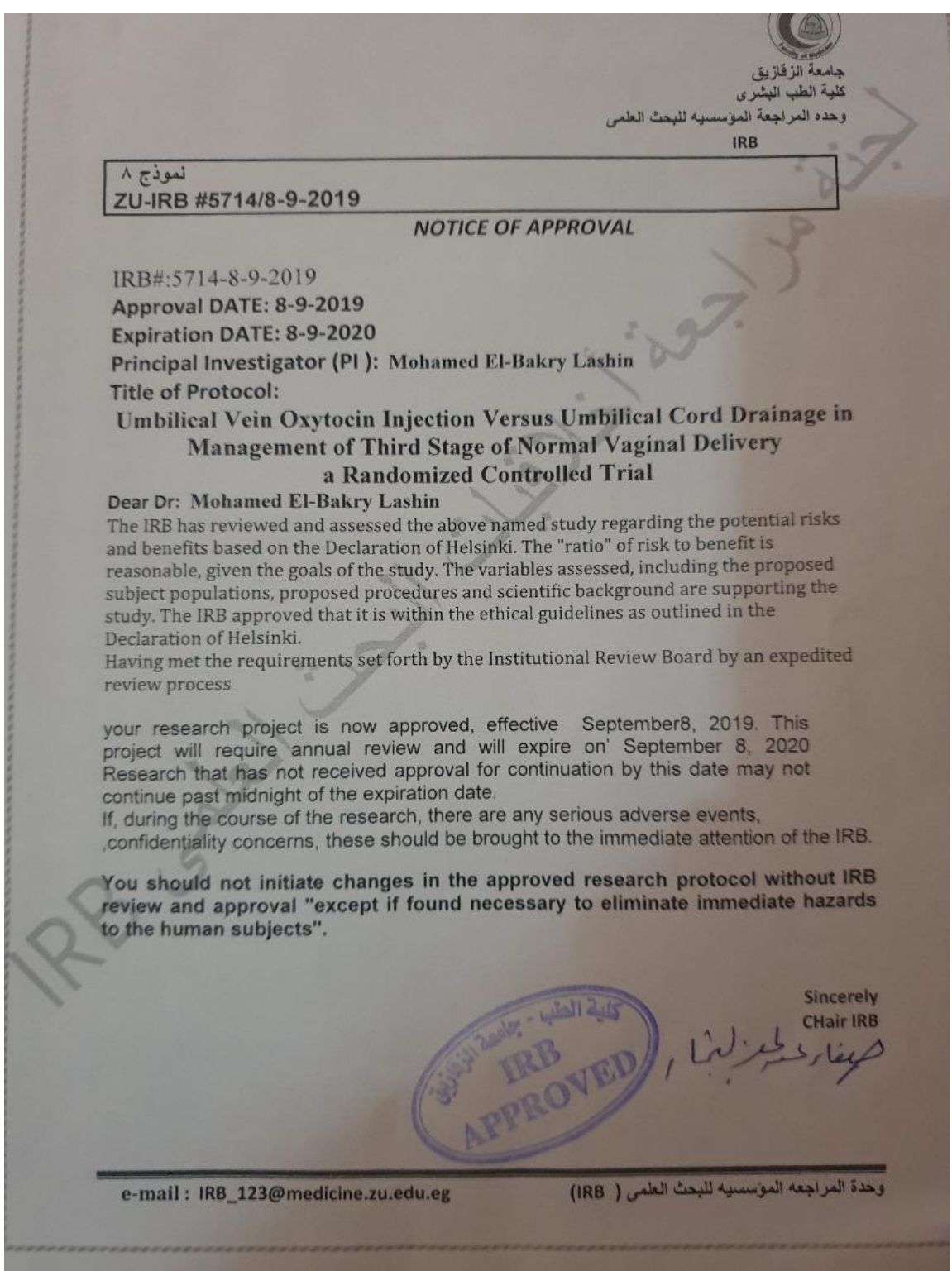

